\title{
La eclosión de las vanguardias en una capital de provincia: política y cultura en el Ateneo de Santander de los años veinte. Entre la tradición y la modernidad.
}

\author{
JERÓNIMO DE LA HOZ REGULES*
}

\section{The emergence of the avant-garde in a provincial capital: the Ateneo de Santander in the twenties. Between tradition and modernity.}

\begin{abstract}
RESUMEN
Analizamos el papel jugado por el Ateneo de Santander de los años veinte, su protagonismo como lugar de encuentro, tribuna de opinión política, cultural y de renovación artística, promotor de las vanguardias plásticas y literarias.

Estudiamos algunas de las polémicas ideológicas y culturales desarrolladas en su seno, la recepción del ultraísmo (1919),

los debates sobre la nueva pintura, el exilio de Unamuno en 1924, el compromiso intelectual de la generación del 27, o las disputas sobre la Dictadura,

también presentes en otros ateneos. Desencuentros, pero también encuentros, como la positiva relación con la Sociedad Menéndez Pelayo y la colaboración intelectual y artística entre los ateneos de Santander y Bilbao.

En su seno se asiste a los primeros alumbramientos renovadores de las artes con sus inevitables debates protagonizados por Gerardo Diego. Como común denominador subyace la búsqueda de la pureza artística, el interés en renovar

las formas, entre los escritores y artistas plásticos, pero con una considerable
\end{abstract}

\begin{abstract}
We analyze the role played by the Ateneo de Santander of the twenties, its role as a meeting place, gallery of political opinion, cultural and artistic renewal, promoter of the avant-garde artistic and literary. We study some of the ideological and cultural debates developed, the reception of the ultraism (Gerardo Diego, 1919), discussions on the new paint, on Unamuno exile (1924), the intellectual involment of the new generation of 27, or disputes on Dictatorship, also present in other ateneos. Disagreements, but also meetings: the positive relationship with the Sociedad Menendez Pelayo and intellectual and artistic collaboration between ateneos of Santander and Bilbao. The Ateneo is the protagonist of the first renewal movements of the arts. Interest in renewing the forms, among writers and artists, but not ideological or political commitments, which appear only timidly, at the end of the Dictatorship. We also studied the more ideologically committed literature and its manifestations.
\end{abstract}

* UNED. Departamento de Historia Contemporánea 
ausencia de compromisos ideológicos o políticos, que sólo aparecen tímidamente, a fines de la Dictadura. También estudiamos la literatura más comprometida y sus manifestaciones, que aunque eclipsada por la renovación del 27, no está tampoco ausente del ateneo, desde los primeros años veinte (José del

Río, Pick, Arturo Casanueva, García Venero, Luys Santa Marina, Ruiz de Villa,

Matilde de la Torre...).

PALABRAS CLAVE:

Ateneo de Santander, Vanguardismo, Intelectuales, Dictadura de Primo de Rivera, Cantabria.

\section{KEYWORDS}

Ateneo de Santander, Artistic avant-garde, Intellectuals, Dictatorship of Primo de Rivera, Cantabria.

\section{INTRODUCCIÓN}

La consulta del archivo del Ateneo, ha permitido rescatar detalles de las relaciones entre los más activos ateneístas, que descubren afinidades que permiten interpretar polémicas en su seno que ligan arte, —las emergentes vanguardias-, ideologías y política. Es el foro por el que la ciudad se asoma a la modernidad vertebrando la opinión santanderina, haciéndose eco de distintos episodios. Tras las disputas entre aliadófilos y germanófilos, surgen sucesivamente polémicas como la irrupción de las vanguardias, los emergentes regionalismos, Annual, la Dictadura, el caso Unamuno, la generación del $27 . .$. Todo ello en el marco del declive del liberalismo, la revolución rusa, o la crisis del 1929, con el auge de los totalitarismos, percibiéndose el nuevo arte y la literatura como motores de transformación de la sociedad.

El ateneo contribuye a dar a conocer a los más jóvenes escritores, políticos, o artistas, algunos de posterior relevancia nacional, Pancho Cossío, Luys Santa Marina, Gerardo Diego, Solana, Víctor de la Serna, Eugenio Vegas Latapie, Maximiano García Venero, etc., frecuentado en los veranos por intelectuales como Marañón o Pedro Sainz Rodríguez. Constatamos por otra parte que en su seno y por extensión en los círculos intelectuales santanderinos, es perceptible un inusual equilibrio, sorprendente por la solidez de la coexistencia entre lo clásico y las vanguardias, renovación y tradición, situación favorecida por el prestigio de la otra gran institución santanderina del momento, la Biblioteca Menéndez Pelayo, enfocada a una promoción del pensamiento del polígrafo, regida por Miguel Artigas, a su vez vicepresidente y director de la sección de literatura del Ateneo, receptivo a las vanguardistas y simultáneamente gestor, en perfecta coexistencia, de los más «ortodoxos» cursos e investigaciones de la Biblioteca. 
Ha sido tratado con profusión el tema de las vanguardias, como motor de cambios, de las «rupturas», pero quizá se ha reflexionado menos sobre estos episodios de convivencia intelectual. Desde una perspectiva ideológica comprobamos que los vanguardistas son acogidos por activos ateneístas ligados a la política conservadora, Pombo y Jose María Cossío, frente a manifiestos más reticentes de los afines al tradicionalismo. Pero a la vez hay críticas de intelectuales, como las del director de La Atalaya, José del Río, Pick, miembro más característico del grupo liberal-conservador, motivadas por la desvinculación de las vanguardias de los compromisos políticos, también manifestadas por otros ateneístas como Arturo Casanueva, o el joven republicano Maximiano García Venero. Vanguardias que son apoyadas por upetistas como los hermanos Cabrero e incluso por Artigas... En una palabra, gran pluralidad de respuestas, sin clara adscripción ideológica ante el nuevo paradigma. Recepción que en cualquier caso es compatible con gran respeto a la tradición, que en el marco santanderino se centraba en la especial vinculación de los grupos intelectuales a la figuras de Menéndez Pelayo y de Pereda. Es el caso de Cossío, de Artigas, Gerardo Diego, o de Victor de la Serna, receptivos ante la modernidad artística pero indudablemente anclados en una tradición, aspecto también perceptible en conferenciantes, como Zuazagoitia, Mourlane, o Basterra, ateneístas bilbaínos invitados, ligados al grupo del Lyon d'Or y consiguientemente a un tradicionalismo clasicista, algunos miembros de la prestigiosa Sociedad Menéndez Pelayo, referente ineludible y que hace de Santander un caso especial, no fácil de encontrar, al unir, en ocasiones en personas muy cercanas, la tradición renovada con las emergentes vanguardias.

En resumen, pluralidad de visiones para un entendimiento más profundo de lo que a primera vista pudiera parecer. Incluso a nivel político, en las disputas sobre la conveniencia de la Dictadura subyace en muchos casos una motivación más de legitimismo en las formas que de verdadera ideología, lo que evita grandes desencuentros, dejando de lado las zancadillas políticas, entre opositores al Directorio como los conservadores Pick, Casanueva, Cossío, o Pombo, incluso Sainz Rodríguez en sus visitas veraniegas, con ateneístas upetistas o afines como Miguel Artigas, Luis Escalante, López Arguello, o Estanislao Abarca, (a su vez devoto de Unamuno). Incluso el entendimiento fue posible entre un Sánchez Mazas, que conferencia reivindicando "que las banderas de Menéndez Pelayo sean nueva bandera de España", acogido en Tudanca en compañía de los conservadores-liberales Cossío y Pick. Artigas, siempre estuvo dispuesto a tender puentes entre el universo cultural representado por Menéndez Pelayo y los herederos de la escuela institucionista, algunos profesores en sus cursos de la Biblioteca Menéndez Pelayo a la que había llegado en 1915 como director, previo paso por el Centro de Estudio Históricos, imbuido de las nuevas tendencias investigadoras que hace compatibles con la promoción del polígrafo, impulsando la construcción del edificio para albergar su enorme biblioteca, inaugurada en 1923 en presencia del rey, sede de los nuevos Cursos internacionales de Verano, frecuentada por escritores, investigadores y con una importante presencia de hispanistas, conferenciantes tam- 
bién en el Ateneo. El ultraísta Gerardo Diego, profesor en dichos Cursos, hará compatible su vanguardismo con el apoyo a sus amigos Artigas y Cossío en la Biblioteca y Sociedad Menéndez Pelayo, segundo pilar, con el Ateneo, sobre los que se articulará la actividad cultural santanderina.

No hay que olvidar en este impulso cultural de Santander, su corte veraniega (Casino, Hotel Real, Teatro Pereda, el naciente «sportismo» del Club Marítimo, Club de Tenis, regatas internacionales, hipódromo, aeródromo...), con la consecuente presencia de políticos e intelectuales. Es preciso recordar que la provincia presentaba los mejores índices de alfabetización de España y la modernización de las artes llegó también tempranamente, en otros campos (Sociedad Cantabria Cines en 1917), a la vez que el café del Boulevard, "de los intelectuales» tuvo que transigir con el primer «jazz band». Ciudad con vocación cosmopolita, se abría también a la ciencia, que indudablemente ejerció como factor modernizador, incorporando una visión más positivista, con el Laboratorio Oceanográfico de Santander, el reclamo del paleolítico cantábrico en el Museo de Prehistoria e inaugurándose, durante la Dictadura, la entonces puntera en España Casa de Salud Valdecilla.

\section{LAS VANGUARDIAS POÉTICAS Y PLÁSTICAS: POLÍTICA Y LA LITERATURA.}

En el Ateneo santanderino dirigido por Gabriel Pombo, en unos dorados años veinte plenos de actividad, se da a conocer la nueva poesía, exponen los pintores vanguardistas (Pancho Cossío, Solana, María Blanchard...), se hace música, pero también -queremos subrayarlo- es donde se deja ver la juventud intelectual socialmente mas inquieta (Arturo Casanueva, Ruiz de Villa, Rodríguez-Alcalde, Matilde de la Torre, Luys Santa Marina, Maximiano García Venero, Eugenio Vegas Latapié) siendo el principal foro en que disputarán poco después, constitucionalistas y upetistas.

Uno de sus primeros logros fue afianzar la emergente vanguardia artística montañesa; siguiendo el ejemplo bilbaíno (con la Asociación de Artistas Vascos, 1911, localista, pero creada con vocación de contacto con las corrientes europeas); Darío de Regoyos apuntaba: «organizan ustedes una exposición sin madrileños, sin sevillanos ni valencianos. ¡Qué delicia! En fin que en dicha exposición habrá extranjeros y algún vascongado solamente. De modo que «habrá arte» gracias a tan buena medida» ${ }^{1}$. Algo similar podríamos decir de Santander, que en agosto del 18 inauguraba con éxito la «Primera exposición artística montañesa», con el propósito de que fuera monográfica de autores de Cantabria y punto de partida de sucesivos eventos (1923 y 1928 en el Ateneo), ligando renacido regionalismo montañés (que fue objeto de debates) con el deseo de mostrar cierto vanguardismo, algo propio de una ciudad que se moderniza. También se dio allí a conocer la nueva arquitectura montañesa, en el marco del nacionalismo español, realidad plural con

${ }^{1}$ BRIHUEGA, Jaime, Las vanguardias artísticas en España: 1909-1936. Madrid: Istmo, 1981 p. 166. 
manifestaciones variadas (el nuevo mudéjar, el plateresco, lo vasco, lo montañés...). Otra exposición de artistas noveles del ateneo de 1925 sirve a estos fines, si bien las experiencias y los compromisos serán como veremos muy dispares en el grupo.

En literatura el veinteañero Gerardo Diego, licenciado en Deusto con su amigo Juan Larrea, se une a la vanguardia, apoyado por el santanderino José Ciría ${ }^{2}$ editor de Reflector (fallecido en plena juventud le dedicó Manual de Espumas, 1924). Invitado por Artigas revoluciona el Ateneo en noviembre de 1919, proponiendo una necesaria renovación poética y artística, el ultraísmo, (cuyo manifiesto de Guillermo de Torre había aparecido el año anterior), lo que motivó hasta cinco sesiones sobre el tema con presencia de músicos, escritores y pintores. En reunión de la Junta de Literatura (JL, 19 y 28-IX-1919) Artigas, en presencia de Diego, reconoce la obligación del Ateneo a recoger este movimiento literario, comentándose un aspecto interesante, como era la variedad ideológica vanguardista, defendida como renovación de todas las artes, aludiendo a un postdebussismo musical, al futurismo pictórico, cubismo... ${ }^{3}$

Lo novedoso del tema, que nos interesa destacar, es que el ateneo, apoyado por sus directivas - burguesía conservadora-, a pesar de las protestas de algunos sectores, se constituye en sede en que confluirán las vanguardias plásticas y literarias, que en armonía se apoyaron mutuamente en su despegue. Así Gerardo Diego dedica versos al pintor Pancho Cossío, que a su vez presta sus pinceles para la portada de su libro ultraísta Imagen y le realizará un retrato; ejemplo que se repite entre otros artistas cántabros. Destacamos la buena acogida de la directiva, y los ataques que estas manifestaciones artísticas recibían en parte del sector tradicionalista, pero también de otros sectores que, como Pick, no comprendían lo que en alguna ocasión tachan de juegos y de falta de compromisos.

La prensa recoge los primeros debates: el autor teatral Santiago Escalera, aunque escéptico, tilda a Diego de apóstol sincero y convencido y deja abierta la puerta a debatir sobre ello (Pueblo Cántabro, 16-XI-1919). La polémica se dispara cuando el 22 de noviembre Diego en segunda sesión sobre «Renovación poética y artística» amplia a todas las artes su defensa de renovación, mencionando la obra del vanguardista pintor santanderino Pancho Cossío, interviniendo en el debate de esa tarde, el arquitecto Elías Ortiz de la Torre, Santiago Escalera Gayé, el canónigo Jaime Espases y el periodista y poeta José del Río, Pick. Estas aperturas no son fácilmente comprendidas por el público, ni siquiera por la intelectualidad. Y queremos detenernos en Pick, cuya poesía estaba imbuída de mensaje social, que apoyado por el mecenas José María de Cossío, iba a publicar, fruto de su repor-

2 DÍEZ DE REVENGA Fr. J. «José Ciria y Escalante y la revista «Reflector» en la primera vanguardia», Monteagudo: Revista de literatura española, hispanoamericana y teoría de la literatura, № 7 , 2002.

${ }^{3}$ VÁZQUEZ LÓPEZ, E. «Artigas ateneísta», BBMP, no XIII, 1947, pp. 52: «Buena cara y mejor talante les puso [Artigas] desde el primer momento a los nuevos poetas de la bulliciosa escuela ultraísta...» 
terismo en Marruecos, versos comprometidos con el extraño título de La belleza y el dolor de la guerra. Pick, inicialmente reacio a las vanguardias, cuyos poemas vacíos no comprende, protesta con «A propósito del ultraísmo: Algo que nuestra timidez nos impidió decir anoche en el Ateneo», (La Atalaya, 23-XI-1919), ridiculizando a los ultraístas, sacerdotes del nuevo altar, ( $L A, 23-X I I-1919)$. Diego replica con «Comentarios a un artículo del tímido de Pick» hablando del ideal de pureza, añadiendo «...no es mi animo entablar una polémica. Para eso está el ateneo»4. Cástor V. Pacheco, con «La poesía ultramodernista» (LA, 26-XI-1919) apunta la inadaptación vanguardista a los principios psicológicos de una poderosa nación en contra de toda una tradición con Menéndez Pelayo a la cabeza, denunciando la actitud favorable de la directiva del ateneo para acoger al movimiento ${ }^{5}$. Pero el ateneo santanderino va a ser receptivo a estas manifestaciones. El pintor y periodista Ángel Espinosa se ve en la obligación de replicar «¿Dónde está la libertad de lengua? ¿Dónde las blasfemias literarias? A no ser que el articulista llame así a todo lo que contradiga su opinión, que todos juzgamos muy estimable, pero no intangible...», provocando la contrarréplica de Luis Iglesias Sainz con «Mas ultraísmo» (El Diario Montañés, EDM, 28-XI-1919) y de Cástor V. Pacheco (PC, 28-IX-1919), que entiende que el ultraísmo es una tomadura de pelo y amenaza a la cultura patria, apuntando que una cosa era la libertad de expresión y otra que el Ateneo se ofreciese para dichas manifestaciones:

«...sigo diciendo que sonroja el permitirse decir [esto], puede discutirse en el Ateneo ¡hasta la blasfemia religiosa!...» La docta corporación ha hecho bien en suscribirse a Grecia y Cervantes [revistas ultraístas], aunque no encontremos en la biblioteca mas que cuatro de las obras de Pereda...»

De Pacheco, periodista tradicionalista, se hace cabeza de turco acusado por los que creen que las vanguardias tienen cabida en el Ateneo; la Junta Directiva no podía permanecer impasible y el 29 de noviembre acordó dirigirse a su socio:

«La Junta Directiva de esta Sociedad, recogiendo el ambiente de disgusto que han producido entre los socios sus manifestaciones públicas sobre el Ateneo, reconoce que sería difícil la situación de Vd. dentro de esta casa sin una aclaración o explicación... [que exige] en carta particular a la Directiva»

En la sesión del 4 de diciembre Pacheco, manifiesta en carta «no haber ido en contra del Ateneo como tal entidad», pero sintiéndose mal visto solicita su baja, siendo respondido por la Junta que «nunca se tuvo propósito de colocar a $V$. en ese trance». El vocal José Ugidos compara el ultraísmo como una plaga en un vergel muy hermoso (JL, 9-XII-1919) y la dividida Junta Directiva del Ateneo, de 13 de enero, ofrece «un voto de confianza al Presidente para solucionar el incidente...».

\footnotetext{
${ }^{4}$ La Atalaya (LA), 24-XI-1919, «El ultraísmo y las escuelas» por G. DIEGO.

${ }^{5}$ GARCÍA DE LA CONCHA, V. «Una polémica ultraísta: Gerardo Diego en el Ateneo de Santander» (1919), en Homenaje al IImo. Sr. Don Ignacio de Aguilera y Santiago, ICC, I, 1981, 175-195.
} 
Fides (EDM, 29-XI-1919) apuntaba con una palabra de claras connotaciones políticas, «Bolcheviquismo literario». El proceso tiene resonancia nacional. El vocal de Artes plásticas y pintor, Gerardo Alvear, se muestra a favor de ofrecer la tribuna a los ultras, así como Manuel Escalera Narezo, que cree necesario dar paso a un arte que desprecie la imitación de la naturaleza (EDM, 6-XII-1919) y el debate prosigue el día 12 de diciembre con la intervención en contra del canónigo Camporredondo, a pesar de su afecto hacia Diego, de Pancho Cossío, que defiende la manifestación ultraísta y del apoyo de Cesar E. Arroyo codirector con Cansinos-Assens de la revista Cervantes. Los debates concluían en enero, apelando el vocal José G. del Diestro a la también necesaria renovación musical.

\section{LAS VANGUARDIAS ARTÍSTICAS.}

Expondrán poco después en el ateneo representantes de las vanguardias artísticas, pintores y escultores ${ }^{6}$, con deseo de nuevas búsquedas, de romper con la mera imagen natural. El profesor José Ugidos (EDM, 6-XII-1919) apuntaba bien a lo que representaban los cambios «hacer arte pictórico arrojando los colores en desorden sobre el lienzo para que ellos por si solos se combinen y formen la obra [...] tiende a suprimir la versificación, que es la gracia de la poesía...». La santanderina María Blanchard ${ }^{7}$ había sido, desde París, pionera cubista, pintora de una realidad deformada subjetiva, geometrizante; a pesar de ser incomprendida el apoyo del mundo intelectual se manifiesta cuando Blanchard vuelve a París ( en decisiva estancia por su contacto con la vanguardia especialmente con Juan Gris) solicita beca a Diputación y Ayuntamiento intercediendo Enrique Menéndez y Pelayo. Gerardo Diego la conocerá durante su estancia en París, admirando "su clarividencia y profundo sentido del arte y de la vida...» (en julio de 1927, en el ateneo, conferencia sobre Juan Gris y el Cubismo).

En resumen es perceptible un considerable compañerismo entre las vanguardias plásticas y literarias y es de destacar que el ateneo va a ser receptivo a sus manifestaciones, a pesar de irritar en ocasiones los gustos de la burguesía que frecuentaba sus salas. Es preciso hacer constar el interés y mecenazgo de determinados ateneístas, sin los cuales el «boom» artístico hubiera sido más atenuado, siendo conocida la labor de su vocal y responsable de Artes, el pintor, luego diputado de Unión Patriótica, José Cabrero Mons y de su hermano Antonio ${ }^{8}$. Algunos pintores montañeses comparten amistad con los Cabrero como Francisco Iturrino, Pacho Cossío, o el pintor y poeta muy presente en el ateneo Ángel Espinosa; men-

${ }^{6}$ SIMÓN CABARGA, J., 1963 Historia del Ateneo, Ed. Nacional, Madrid, pp. 93-102. Vid., CRESPO LÓPEZ, M., El Ateneo de Santander, 1914-2005, Santander, CEM, 2006.

${ }^{7}$ María G. Blanchard (1881-1932), la pintora más destacada del cubismo, nacida el mismo año que Picasso, Gargallo o Vázquez Díaz.

${ }^{8}$ José Cabrero Mons, presidente de la Sección de Artes Plásticas (1924-1926) Involucrado en la vida artística, amigo de Solana, había sido pintor y recorrido el París de la «Bohemia». 
ción aparte merecen otros artistas menos en línea vanguardista, como Ricardo Bernardo que se da a conocer en el Ateneo en 1918 causando admiración por sus tipos montañeses, —el Pereda de la pintura se decía-, y expuso en varias ocasiones en el Ateneo hasta su exilio.

Eran célebres las tertulias del Ateneo, con Cossío, Estanislao Abarca, Flavio San Román, Gerardo de Alvear ${ }^{9}$, (primer presidente de la sección de Artes Plásticas y artífice, con su sucesor en la sección, José Cabrero de la promoción de los jóvenes pintores), Cesar Abín ${ }^{10}$, escultores, como el palentino-montañés Victorio Macho o Daniel Alegre ${ }^{11}$, o músicos como García del Diestro. Sin olvidar la sombra siempre presente de los montañeses más alejados, en París, o en Madrid como Gutiérrez Solana, que expone en el ateneo en 1921, 1927 y 1928 (con sus crudos motivos con un expresionismo propio, alejado tanto de lo académico como de vanguardias), que frecuentaba la tertulia de Pombo, inmortalizándola en uno de sus cuadros en que aparece con Gómez de la Serna y con el santanderino José Cabrero.

Las exposiciones vanguardistas se suceden en el Ateneo, proyección impulsada por Alfonso XIII que realzaba estos eventos veraniegos con su presencia: en 1920 asistía a la exposición de Francisco Rivero Gil ${ }^{12}$, herido en el Rif, comentaba las penalidades con caricaturas de soldados, en un momento en que ese dolor era aún asumible.., nuestros ejércitos no habían sufrido aún la prueba de Annual que sorprendería, veraneando en Santander a los reyes en 1921 marcando un claro punto de inflexión política... No podemos dejar de citar, por las siempre controvertidas relaciones entre arte y política, al pronto alejado de Santander, el muralista Luis Quintanilla, que pasa a fines de la Dictadura al socialismo como Ricardo Bernardo ${ }^{13}$, despedido con versos de Pick, leídos por Cossío, camino de América en 1924, (Argentina fue lugar de destino preferente de breves estancias o de años, de varios creadores santanderinos, (Alvear, Abín, Espinosa, Bernardo, Consuelo Berges, o Gerardo Diego).

Por otro lado el pintor más destacado, y cuya presencia deja huellas profundas en el arte y la política es Pancho Cossío (1894-1974) ${ }^{14}$; futuro dirigente falangista, invita a la sociedad santanderina a la búsqueda de un cosmopolitismo que veía como absolutamente necesario en aquellos momentos de cambios; expone en 1921 y 1922 provocando polémica con cuadros como su Camouflage o Traineras,

\footnotetext{
${ }^{9}$ Gerardo de ALVEAR primer presidente de la sección de Artes Plásticas del Ateneo. Muralista con estancias en Francia y Argentina y eslabón entre los paisajistas montañeses y las vanguardias.

${ }^{10}$ César G. Abín, (1892-1974), joven alumno de Blanchard, luego discípulo de Muñoz Degraín expone en 1915 en el ateneo, pasando a París gran parte de 1924-39.

11 SIMÓN CABARGA, J. Daniel Alegre, «Antología Escritores y artistas Montañeses», Santander, 1950.

${ }^{12}$ Francisco Rivero Gil, (1899-1972). Exiliado con la guerra.

${ }_{13}$ Vid. LÓPEZ SOBRADO, E., Ricardo Bernardo (1897-1940), Santander, Museo de Bellas Artes, 1997; idem, «El pintor Luis Quintanilla, espía en la embajada», Pluma y Pincel,9 (2002), pp. 37-41.

${ }^{14}$ Cossío en París frecuenta a Buñuel que se enemistó con él a su giro falangista, MADARIAGA, B. y HOZ, Angel de la, Pancho Cossío. El artista y su obra, Ayto. de Santander, Santander 1990.
} 
o incomprensión por su desprecio de las formas en aras de la abstracción y del color. Creemos que de forma similar a lo que hemos visto con Diego, la procedencia santanderina, conservadora y burguesa de Pancho Cossío le ayuda a ser comprendido, aunque quizá un poco a la fuerza: a pesar de su desconcertante modernismo colorista y planista no se le puede negar que es artista concluía el diario católico (EDM, 23-IV-1923).

Con, «El arte rebelde de Francisco G. Cossío: El pintor defiende su obra», sale a la palestra ( $L A, 16-V-1922)$ y aboga por una renovación, a imagen de París:

«...que se asomen a los Pirineos y desde allí contemplen el panorama estético de Europa y... entonces comprenderán [...] cosas que hoy son arcanos para ellos. [...] no se nos tome por iconoclastas. No lo somos. Solamente somos hombres que honradamente intentamos crear un nuevo valor estético por insignificante que sea. Para conseguirlo seguiremos trabajando aunque los perros ladren».

Cossío, que conocía ya a las vanguardias madrileñas, expone en el ateneo de Madrid en 1923, coincidiendo esas semanas con una conferencia ateneística de un Gerardo Diego ya reconocido, Estética y poética, leyendo poemas de Imagen, algunos dedicados a las vanguardias pictóricas como en Manual de espumas y acoge afectuosamente la obra de Pancho (a quién dedicó el poema Puerto Chico en 1919) defendiendo su originalidad creadora, correspondido por éste, que presta sus pinceles para la portada de su ultraísta Imagen (Veleros, de Pancho, perteneció también a Gerardo Diego). Diego propone en prensa al pintor, que «vaya a Italia y a París [...] para desarrollar sus envidiables dotes» a donde finalmente viaja, en noviembre de 1923, en compañía del escultor cántabro Daniel Alegre, (abandonando ambos sendas vocalías de artes en el ateneo de Santander para las que habían sido elegidos, lo que prueba una vez más su grado de aceptación allí) donde se consagra y colabora con Buñuel... Comentaba Diego: «[Pancho] Cossío el cojo ha tenido un gran éxito de crítica con un solo cuadro en el Salón de Otoño. Me escribe muy contento.... ${ }^{15}$.

Finalmente José del Río Sanz 'Pick' cuyas críticas iniciales a la vanguardia hemos comentado, se suma a su manera a la provocación vanguardista pidiendo a Cossío que ilustre con xilografías su libro Hampa (1923), de tema escandaloso pero ejemplo de sus preocupaciones humanistas hacia las capas más excluidas de la sociedad, —con gran indignación de Artigas, hemos decidido hacer una tirada clandestina-, comunicaba Pick a José María de Cossío, que destaca el éxito de las trabajadas xilografías, que reciben el elogio de Diego ${ }^{16}$.

Hay que dejar constancia de que las vanguardias plásticas montañesas, de las que quizá Pancho Cossío sea el más destacado, desempeñaban un buen pa-

${ }^{15}$ GÓMEZ DE TUDANCA Rafael, G. Diego- J.M. de Cossío Epistolario. Nuevas claves de la generación del 27, prólogo de E. de Diego, Madrid, Univ. Alcalá, FCE, 1996. [71] GD Gijón, 5 de noviembre 1925.

${ }^{16}$ ACT, Pick a Cossío, 21-II-1923. G. Diego en LA, 13-VI-1923. 
pel en el entonces inquieto arte nacional (si bien sin conciencia clara de grupo «montañés»). Las nuevas tendencias se consolidaban en España, seguidas de cerca por los santanderinos; el madrileño "Salón de Arte Moderno", la exposición pintores íntegros, (en que María Blanchard aparece como una figura relevante) ${ }^{17}$, la tertulia en «Pombo», la ruptura vanguardista con la Exposición Artistas Ibéricos, de 1925 en el Retiro con los santanderinos Victorio Macho y José Gutiérrez Solana. En conferencias y manifiestos se dejan ver anhelos globales de cambios sociales no siempre concretizados y en algunos casos se expresan las ideas políticas de los intelectuales y artistas. Impacto cultural que destacaba el propio Ortega en La deshumanización del arte (1925). También se otorga el Premio Nacional de Literatura a la vanguardia literaria, Alberti y a Gerardo Diego por Versos humanos, casi a la vez que Guillermo de Torre publica Literaturas europeas de vanguardia.

Sin embargo, queremos destacar que la nueva creación plástica como tampoco la creación literaria que se dejaba ver por el ateneo santanderino no era ni en el fondo ni en la forma monolítica. En literatura no sólo es perceptible la más famosa generación del 27, vanguardia de gustos entonces puramente estéticos, sino que existen otros jóvenes escritores en Santander, entre ellos Arturo Casanueva, Luys Santamarina (desde la derecha), Maximiano García Venero (que del radical-socialismo pasa a falange), o más a la izquierda Consuelo Berges, Matilde de la Torre, o Manuel Ruiz de Villa (influido por Unamuno y Wescenlao Roces), e incluso la preocupación social es perceptible en Eugenio Vegas y José María Rodríguez-Alcalde (entonces tradicionalistas, como también el, —desde muy joven ausente de Santander-, José Antonio Balbontín, que pasa de tradicionalista a comunista), que pertenecen a un grupo de jóvenes intelectuales que son la "otra generación del 27", que en los años de la dictadura, en sus textos no buscan una mera estética sino que persiguen cambiar cosas ${ }^{18}$; es por tanto otra cara distinta a esa juventud «apolítica» que se ha querido hacer más representativa de la época, que tuvieron su particular 98 en el desastre de Annual, (el escritor Casanueva se alista al tercio, el periodista José del Río, Pick, es reportero en Marruecos y Luys Santamarina escribe sobre la guerra) de donde regresaron con la convicción de que había que transformar España.

Asimilable por edad a la generación del 14, José del Río Sainz, Pick, premio Fastenrath, poeta del pueblo, de amistades en todos los ambientes, —había sido marino mercante- sus versos se leen en los ateneos norteños. Es otra de las más influyentes plumas del momento, principal creador de opinión e ideología a nivel popular, del mismo modo que Miguel Artigas, Gerardo Diego, o José María de Cossío, ejercen una indudable influjo sobre las capas más cultas. Su grado de conocimiento del día a día es elevado como denotan sus editoriales en La Ata-

17 GÓMEZ DE LA SERNA, R.: La sagrada cripta de Pombo, Hernández y Galo Páez, Madrid, 1918.

${ }^{18}$ BOETSCH, Laurent, José Díaz Fernández y la otra generación del 27, Madrid, Pliegos, 1985. 
laya, en evolución ideológica de un carlismo juvenil al conservadurismo republicano; adquirió fama como reportero en África tras Annual, con impactantes artículos ${ }^{19}$ : como en el caso del procesamiento de Giménez Caballero por sus Notas marruecas de un soldado (1923), algunos de sus artículos, como «El legionario que vimos morir» y «Más amargas verdades», le valdrán unos días de cárcel en 1921. Este fondo social es frecuente en Pick, que había sufrido las penalidades de años de marino mercante por todos los mares, plasmado en Versos del mar y de los viajes, o en Hampa, preocupación perceptible en algunos pintores como Rivero Gil al plasmar sus impresiones africanas, pero en general ausente en los jóvenes de la generación, ajena impactos como la guerra europea que había marcado tanto a la generación del 14, como Artigas:

«...para la generación que, atraída irresistiblemente por el prestigio de la cultura europea [...] fue la gran guerra una sacudida terrible que hizo volar de nuestras cabezas muchas ilusiones. El nimbo semidivino de la cultura de Europa comenzó a esfumarse; [...] me ayudó a vencer la crisis y avivó la fe naciente de mi nuevo ideal: conocer, difundir y continuar las enseñanzas de Menéndez y Pelayo» 20

\section{LAS POLÉMICAS POLÍTICAS. EL CASO UNAMUNO.}

Algunos de estos escritores más comprometidos van a ser protagonistas de nuevas polémicas en la Dictadura. Igual que en el Ateneo madrileño, en el de Santander, aunque la pluralidad era evidente, era notorio que algunos de los miembros gustaban de un calculado distanciamiento respecto a la Dictadura, quizá en parte como una actitud de rebeldía ante los ataques de ésta a la vieja política, en la que bastantes se veían reflejados ${ }^{21}$. Preside el Ateneo, sin apenas oposición, Gabriel Pombo Ibarra, exdiputado provincial, muy próximo al jefe provincial conservador Juan José Ruano de la Sota, (en ostracismo político desde el golpe, tras ser fugaz exministro con Sánchez Guerra, a cuya caída se le había organizado importantes homenajes en el ateneo y en el Círculo LiberalConservador de Santander ${ }^{22}$ ); Ya meses antes al advenimiento de la Dictadura, en una sesión de la Junta de Trabajo del Ateneo, 20 de mayo de 1923, presidida por Miguel Artigas, se da lectura a la invitación del Ateneo de Madrid para que el de Santander se adhiera a la campaña para exigir las responsabilidades por Annual; ese verano del 23 se había intentado invitar a Unamuno al Ateneo sin éxito:

\footnotetext{
${ }^{19}$ VVAA, Homenaje a José del Río Sainz, Pick, ICC, Santander, 1974.

${ }^{20}$ Don Carmelo de Echegaray, Conferencia leída en la sesión de homenaje que la Junta de Cultura Vasca, Bilbao. Imp. de la Excma. Diputación, 1929, pp 6.

${ }^{21}$ Vid. GARCÍA QUEIPO DE LLANO, G. Los intelectuales y la Dictadura de Primo de Rivera, Alianza Ed. Madrid, 1988, pp. 52 y sgs.

${ }^{22}$ En el Ateneo (23-XII-1922) y en el Círculo Liberal-Conservador (Epoca, 25-XII-1922).
} 
«se le intentó llevar al Ateneo pero [...] costó mucho vencer resistencias y recelos, hubo discusiones acaloradas y cuando se consiguió la autorización para la conferencia, don Miguel tenía ya la maleta preparada para marcharse ${ }^{23}$

Una primera reticencia de la directiva del Ateneo a manifestar cualquier tipo de apoyos al Directorio es palpable ya en la Junta de 25 de octubre de 1923:

«ha sido pedida la tribuna del Ateneo para dar una conferencia acerca de la actualidad, planes y procedimientos del Directorio [...]. Se acuerda que siguiendo el procedimiento establecido por el Ateneo para todo lo que se relacione con política viva con toda clase de eufemismos, sea denegada la tribuna».

Esta exclusión de cualquier acto de apoyo a la política del Directorio contrasta con el buen recibimiento con el que se acogió algún homenaje a dirigentes conservadores, «que aparezca dado, no por el Ateneo, sino por socios... ${ }^{24}$. En octubre de 1924 por primera vez se vislumbra una maniobra de intelectuales afines a la Unión Patriótica para desplazar a Pombo de la presidencia; el ambiente estaba enrarecido, tras la difusión de los escritos de Blasco lbáñez contra Primo de Rivera desde París. Poco antes El Cantábrico (EC, 10-10-1924) se hacía eco de una entrevista al catedrático Pedro Sainz Rodríguez, asiduo de la Biblioteca de Menéndez Pelayo, protagonista de una famosa protesta que le valió la felicitación de Unamuno y de Cossío, que comentaba su disconformidad con el régimen a Artigas:

«¿Asististe al banquete de Sainz? Cuéntame cosas de él. Parece que el ambiente político se le enrarece cada vez más al dictador -Mambrú se fue a la guerra...,- ésta le sostiene.... ${ }^{25}$

Comentaba Pick el interés político, en ocupar la presidencia del ateneo manifestando que, aunque ambos bandos se hayan lanzado a una lucha en busca de los votos, la clase intelectual no se compra tan fácilmente..., frase significativa, que nos lleva a encontrar similitudes con otros muy estudiados conflictos ateneísticos.

«uno de los dos bandos ha ido de puerta en puerta pidiendo votos y comprometiendo a la gente como en otros tiempos y para otra clase de candidaturas [...] el mismo Pueblo Cántabro [maurista] que tuvo siempre para el Ateneo y para sus hombres una frase mordaz o un olímpico olvido, ahora parece muy preocupado [...], pero la elección de Pombo ha sido honrosa...»26

Artigas, el perdedor, comentaba a Cossío desmarcándose de la iniciativa: «Ya hay nuevas juntas en el Ateneo. Los insurgentes quisieron dividir la horca. Por ahora hay fidelidad al Magzen... "27. Años después dimitirá con otros ateneístas de

\footnotetext{
${ }^{23}$ PICK, Aire de la Calle: «Don Miguel de Unamuno en la Montaña», LVC 11-VIII-1929.

${ }^{24}$ Archivo del Ateneo de Santander (AAS), Libro de Juntas de G., 9-XII-1923, presida por Pombo.

${ }^{25}$ Archivo de la Biblioteca Menéndez Pelayo, (ABMP), Correspondencia Artigas, s/f sobre 1925.

${ }^{26}$ La Atalaya, (LA), 15-XI-1924. «Lo que ocurre en el Ateneo» por Pick.

${ }^{27}$ MA a Cossío 1925?; en Morelli, op. cit.., pp. 172.
} 
la presidencia de la sección de Literatura del ateneo, en 1928 en protesta por las intromisiones del presidente, y comentaba a Sainz Rodríguez:

No queda espacio para hablar de política: mejor [...] Lo poquísimo que he actuado me la hace repugnante. Se desnudan demasiado los hombres y eso es poco estético ${ }^{28}$

En este marco de desarrollan polémicas sobre el caso Unamuno, que amigo de los Cossío, poco antes del golpe había pasado unas semanas en Tudanca, sin conseguirse su presencia en la tribuna del Ateneo solicitada por Pick. Gerardo Diego, con apoyo de Cossío, seguirá pendiente de Unamuno al que visitará en Paris con Larrea y Huidobro, así como a Juan Gris y otros cubistas ${ }^{29}$. Su destierro y los sucesos del ateneo madrileño ${ }^{30}$, van a tener eco en las tertulias del Ateneo y en la prensa, como el asunto Blasco lbáñez, que con ocasión de los sucesos de Vera de Bidasoa, de noviembre de 1924, comenzó a recrudecer su campaña contra la monarquía y contra Primo de Rivera. Pick reconocía el error de Blasco en insultar al rey, aunque desaconsejaba los ataques a su obra y destacaba la importancia de la figura de Alfonso XIII, como defensor de las libertades públicas y su liberalismo:

«Sentimos por la personalidad moral y docente de D. Miguel de Unamuno una veneración sólo inferior a la que sentimos por D. Alfonso XIII... Se ataca a Blasco Ibáñez que pudo equivocarse...»31

Al día siguiente, el ateneísta Rodríguez-Alcalde, respondía con quejas por la postura antimonárquica de Unamuno y Blasco Ibáñez. Vocal de la Federación de Estudiantes Católicos, potente asociación en la que colaboraba, con el jovencísimo Eugenio Vegas Latapié, Rodríguez-Alcalde pedía a los intelectuales no enaltecer a los que considera conspiradores: "Unamuno, ¿no ha injuriado varias veces al rey?, ¿no es notoria la inmoralidad de Blasco Ibáñez?», apuntando que su fama es injustamente exagerada por algunos grupos ${ }^{32}$, manifestando así lo que era notorio en aquellos días en editoriales de La Nación o El Debate ${ }^{33}$; Siguiendo en cierto modo las opiniones que había manifestado Maeztu en prensa sobre las contradicciones de sus obras, apuntaba que no se puede afirmar -replica Rodríguez Alcalde- que «sea Unamuno un filósofo, aunque tenga ambición filosófica...» ello, no impide a Rodríguez-Alcalde felicitar esas mismas semanas a Pedro Sainz Rodríguez, por su famoso discurso de apertura de Curso 1924-25, de la Universidad Central, sobre «Evolución de las ideas sobre la de-

\footnotetext{
${ }^{28}$ Archivo Fundación Universitaria Española, (FUE), Fondo PSR, 1/3-132, Artigas a Sainz Rodríguez, 30-11-25.

${ }^{29}$ G. DE TUDANCA, R. Op. Cit., Epistolario... [42] JC. Tudanca, 9 [septiembre 1924].

${ }^{30}$ Vid. RUIZ SALVADOR, A. Ateneo Dictadura, República, F. Torres, ed., Valencia 1976, 284 pp.

${ }^{31}$ La Atalaya, (LA), 18-XII-1924.

32 José $M^{2}$ - G. Rodríguez-Alcalde, en LA, 19-XII-1924; le contesta Pick en LA, 18 a 20-XII-1924.

${ }^{33}$ El Debate, 23-2-24: «Justo y Popular: El destierro de Unamuno», 2-11-1924 «Lo del día: Blasco Ibáñez»; 3-12-24: «Una cruzada moral: Embajadas intelectuales».
} 
cadencia española»34, —discurso en la línea de Menéndez Pelayo pero que tuvo resonancia como plataforma de protesta a la dictadura-, ni ser el organizador de un banquete a Pick para pedir su nombramiento como hijo predilecto de Santander ${ }^{35}$. Como vemos las discrepancias políticas no impedían una buena armonía de fondo entre los intelectuales santanderinos conservadores o defensores de la Dictadura, cuyas posiciones ideológicas no eran en un buen número de temas, tan distantes.

Pick responde a su amigo el columnista Rodríguez-Alcalde, entendiendo que es un deber defender a estos escritores no ya como políticos, sino como «hombres grandes de España»; la moral poco tiene que ver con la grandeza literaria de Blasco Ibáñez, replica dedicando en La Atalaya unos versos a don Miguel entonces en París. Pick en «La madriguera del león», publicado a la muerte de Blasco, abundará en este tipo de defensa basada en la talla literaria y en su convicción de la importancia de, aún siendo discutibles las ideologías, tener compromisos intelectuales, que aunque de signo diferente, estaban presentes también en los polemistas de la Federación de Estudiantes Católicos, Rodríguez-Alcalde o Vegas Latapié, pero cuya ausencia en la juventud de los años veinte, cree nociva:

«Nosotros recordamos nuestra infancia de «requetés», cuando nos crispábamos de ira ante los nombres de Azzati y Blasco. Estando entonces tan distantes de ellos, estábamos sin embargo mucho más cerca que la actual juventud, no estremecida por ningún impulso romántico» ${ }^{36}$.

En la misma línea de Pick se sitúa Manuel Ruiz de Villa, posterior diputado en la república, exalumno y defensor de Unamuno y colaborador de La Atalaya. Crítico con la Dictadura en el Ateneo defendió convocar elecciones (diciembre de 1925) tachando a la España actual de indiferente y cementerio de espíritus. Colaborador en Santander en la difusión de Hojas Libres, su libro Sobre el corazón del silencio ${ }^{37}$ es con seguridad el texto más representativo de la oposición intelectual al directorio, recogiendo conferencias del Ateneo, «Salud y enfermedades del Estado» $y$ «La vida publica» comentando acontecimientos como el politizado homenaje a Ganivet, pero también preocupado por la situación de desintegración en «El desmenuzamiento de España». Pick apoya a Unamuno con un poema y alaba a Manuel Ruiz de Villa: «...como ayer a [Luys] Santa Marina, hoy saludamos el advenimiento a la república de las letras de otro mozo [...]; oyó las lecciones del glo-

${ }^{34}$ SAINZ RODRÍGUEZ, P., Testimonio y recuerdos, Barcelona, Planeta, 1978. pp. 86-89. El Cantábrico 10 y 11-X-1924, sus declaraciones; Es significativo que el esperado discurso de PSR, de 19 de diciembre de 1924, La evolución política española y el deber social de los intelectuales, (Madrid, Imp. Tejada, 1924) es realizado en línea conciliadora defraudó a la oposición más dura.

${ }^{35}$ FUE, Fondo PSR, № 963, 1/2-479, R-Alcalde, 8-XI-1924. Vid. ESCRIBANO, Julio, De la monarquía a la república, pp 89.

${ }^{36}$ Pick, La Voz de Cantabria (LVC), 27-XII-1928: «La madriguera del león».

${ }^{37}$ RUIZ DE VILLA, Manuel, Sobre el corazón del silencio, Imp. Martínez, Santander, 1925, pp. 91. ACT, Río a Cossío, 15-VI-1924. Vid. LA 19-XII-1924 y 8-X-1925: «La sensibilidad de un pueblo».

Vid. PASTOR, J.M., Leyendo a Pick, APS, Imp. Calima, Santander, 2007. 
rioso Unamuno y está compenetrado con Roces [que] redacta El Estudiante»38. Presenta el libro, reclamando todos los derechos, todas las libertades, el ateneísta Arturo Casanueva escritor comprometido, voluntario en Melilla y autor de «La ruta aventurera de la cuarta salida» ${ }^{39}$, que le valió un juicio militar, con portada del pintor Flavio San Román, la legión hecha carne, según Pick su prologuista.

Volviendo a la polémica por el destierro de Unamuno, José María de Cossío tercia en prensa escuetamente, posiblemente para evitar incrementar la tensión dada su amistad con intelectuales de la UP, pero afirmando, para evitar dudas, su lealtad monárquica:

«El Sr. Unamuno nunca ha faltado a clase y el decirlo es en Usted [Rodríguez-Alcalde] un error de buena fe [...]; la razón de su destitución no fue ninguna indignidad, sino una cuestión menudísima de la política vieja [...] y me sumo a toda campaña que se haga en post del prestigio de la monarquía» 40

Un Cossío sin embargo crítico con la Dictadura, que comenta en carta a Gerardo Diego, «Aquí hemos celebrado la memoria de Ganivet con diversas amenidades antidirectoristas ${ }^{41}$ y se disgusta con la aproximación de Azorín a la Dictadura, o comenta a Ortega y Gasset: «Está muy bien filosofar-querido Ortegapero hay que resolver antes una cuestión previa, de dignidad, de decoro en la que humillantemente estamos y con lo que al olvidarlo colaboramos sin querer»42. Francisco de Cossío, que había hecho pública su lealtad al entonces perseguido Santiago Alba y su apoyo a Unamuno, sin embargo le comentaba:

«Yo había soñado con la posibilidad de una reconciliación [...] en Tudanca advertí, por ciertos detalles, que la concordia entre el rey y usted no era imposible [...] se ha agrandado la distancia. Pero no desconfío. Y sueño todavía con la reconciliación!» ${ }^{43}$.

Francisco de Cossío, decidió también exiliarse en París (tras ser recluido dos semanas, abril del 26 , en las Chafarinas, con Jiménez de Asúa y el santanderino Arturo Casanueva, abogado y escritor, envuelto en un capote militar de la Legión Extranjera, con un kodak en una mano y una máquina de escribir en la otra, siempre dispuesto a defender las posiciones de Alba y Sánchez Guerra ${ }^{44}$. José María,

\footnotetext{
${ }^{38}$ El Impulsor de Torrelavega, 26-VI-1926.

${ }^{39}$ CASANUEVA, A., La ruta aventurera de la cuarta salida, Imp. Martínez, Santander, 1923, 222 pp.; $L A, 1-3-1923$; $L A$, Solano, 8-3-1923: «cuya ingenua sinceridad emociona».

40 LA, 19-XII-1924.

${ }^{41}$ G. DE TUDANCA, R. Epistolario... [58] JC: Valladolid 29-3-25. 1928.

${ }_{2}$ Fundación Ortega-Marañón, (FOM), Correspondencia Ortega, C-58-6ª , Cossío a Ortega, 2-III-

${ }^{43}$ ACT, Carta a Unamuno s/f. de Cossío (de Francisco según_CRESPO LÓPEZ, M., Vida de Cossío hasta la guerra civil, 1892-1939, Icom Global S. L., Maliaño, 2010 pp. 117 y 119. El 17-X-24 en carta desde París a JMC arremete contra la Dictadura (en GÓMEZ DE TUDANCA, Semblanza y obra de José María de Cossío, Santander, SMP, 2000, pp. 71).

${ }^{44}$ COSsío, Fr. de, Testigo de una época, Espasa-Austral, 1988, pp. 86 y 177, «Cazadores de gorras» (10-VI-24), ridiculiza a la Unión Patriótica. LA, 20-V-1926 «Crónica de Chafarinas» por Fr. de Cossío.
} 
en carta a Diego, alude a los hechos, que contribuyeron a apartar aún más a los Cossío del régimen:

«Te agradezco infinito tus palabras sobre el atropello de Paco [...] la causa ha sido el artículo que publicó en La Razón de Buenos Aires en setiembre y principalmente lo que en él decía sobre Delgado Barreto » ${ }^{45}$.

Francisco de Cossío conferenciaría meses después en el Ateneo de Santander y publica "Cuaderno de un confinado español» editado por La Atalaya de Pick, en $1927^{46}$, dedicado al exministro Santiago Alba, jen plena Dictadura!. El "caso Unamuno», las críticas vertidas por Blasco Ibáñez, o los sucesos del ateneo, sirvieron para mostrar posicionamientos a favor o en contra del gobierno, pero que no llegaron a romper, durante la Dictadura la general concordia entre los distintos grupos de intelectuales montañeses. El Ateneo en 1925 homenajea unánimemente al poeta y presidente de Diputación, Alberto López Arguello, a pesar del calculado distanciamiento que hacía que polémicamente, en abril de 1928, la presidencia decida no adherirse a un homenaje del ayuntamiento a Primo de Rivera.

\section{GERARDO DIEGO, UNA ¿RUPTURA? VANGUARDISTA.}

Otra controversia con importantes ecos santanderinos que queremos destacar en los años de la Dictadura, también con implicación de los intelectuales, coincide con la consolidación de Gerardo Diego, Premio Nacional de Literatura (1925) que es homenajeado, aunque no todo son adhesiones, como le comenta su confidente Cossío:

«Tu Manual de espumas se lee aquí e indigna; no es mala señal. Es el libro de la no conformidad, que diría Eugenio d'Ors ${ }^{47}$ [...] la mayor parte de los que podrían haber hablado no saben qué decir de él» ${ }^{48}$.

Su hermano el padre Sandalio Diego, le manifiesta dudas sobre su vanguardista Imagen que entiende quizá «para complacer, a lo que pienso, a muchos de tus amigos» ${ }^{49}$. A pesar de su continua oscilación entre vanguardismo - esencial para adquirir fama- y versos clásicos, la poesía de Diego es globalmente bastante bien considerada desde distintos sectores intelectuales, («Soria» tuvo una acogida

${ }^{45}$ GÓMEZ DE TUDANCA, R. Epistolario... [91] Valladolid, 4 mayo 1926.

${ }^{46}$ COSSíO, Fr. de, Cuaderno de un confinado español, Santander, Imp. La Atalaya, Pról. de Manuel Sandoval, epílogo de J.Mํㅡ. de Cossío. El 17-X-24 en carta desde París a JMC arremete contra la Dictadura, en GÓMEZ DE TUDANCA, Op. Cit.., 2000, pp. 71.

${ }^{47}$ GÓMEZ DE TUDANCA, R., Op. Cit., Epistolario... [59] JC: Valladolid, 14 mayo 1925.

48 idem [63] JC: 10-VI-1925 y [94] 27 de octubre de 1926.

${ }^{49}$ Carta de Sandalio a GD, 25-IV-1922 en Rubio Martín, T. Gerardo Diego y su pensamiento religioso, Ed. Monte Carmelo, Burgos, 2011. 
más mayoritaria). Pero Pick, critica a Diego por no involucrarse más en política y pone el ejemplo de Marañón, invitado con enorme éxito al Ateneo santanderino, (las conferencias en estos años de Ossorio, Marañón, o Sainz Rodríguez fueron aprovechadas por Pick en este sentido), comentando la situación política que afectaba al ateneo madrileño:

«[Gregorio Marañón] capitán de la mermada tropa de los hombres que piensan y sienten «avante»,' nos saludó en nombre del ateneo de Madrid el cual -dijoestá ahora en estado cataléptico hasta que vuelva el librepensamiento» "50.

El Centenario de Góngora ${ }^{51}$, al que La Gaceta Literaria dedica un número, cohesiona a la incipiente generación del 27 con participación santanderina decisiva de Cossío, Gerardo Diego y de Artigas, (premio de la RAE en 1925 y Nacional de Literatura, 1927) ${ }^{52}$. Pero en estos años centrales de la Dictadura la nueva generación vanguardista, purista y de vocación más cosmopolita que las precedentes, que se centraban en los problemas patrios, no se sentía obligada a un compromiso de tipo político-social como el asumido por las generaciones del 98 y del $14^{53}$. Por ello no es sorprendente que ni Unamuno, ni Juan Ramón Jiménez, ni Valle Inclán, entre otros, quisieran involucrarse en celebrar un evento que, como intuía Ortega, se convertía en algo puramente estético ${ }^{54}$ : Diego se burla de estas actitudes con inocentes provocaciones:

«en Madrid [...] Hay que armar algún escándalo... Con menos de apedrear la casa de Valle-Inclán e ir a la Comisaría no me conformo. Sin noticias jdesde marzo! De José María de Cossío. Y poco menos de los demás gongorinos» ${ }^{55}$.

Gerardo Diego reta en cierto modo a Ortega y le avisa del ataque de que va a ser objeto en la revista Lola por haber desdeñado la poesía joven:

«debemos cumplir nuestro deber de irrespetuosidad, perfectamente compatible con la estimación literaria y el respeto [...] ustedes los mayores, podían permitirse el lujo de desdeñarnos o atacarnos injusta y, a veces, groseramente [...] y nosotros, tan seriecitos y tan buenos chicos, llamándoles genios todos los días ¿No es verdad que es absurdo? ${ }^{56}$

En cualquier caso el creciente protagonismo de Gerardo Diego le supuso, contra su voluntad, ser adscrito ideológicamente. Se iniciaba así «el demonio de la

\footnotetext{
50 Pick, LA, 12-I-1926: «El doctor Marañón en el Ateneo» .

${ }^{51}$ MORELLI, G., Gerardo Diego y el III Centenario de Góngora (Correspondencia inédita), Pre-Textos, 2001, Valencia.

${ }^{52}$ ARTIGAS, M., Don Luís de Góngora y Argote. Biografía y estudio crítico, Madrid, 1925 y Semblanza de Góngora, 1927, Madrid, Lib. Fernando Fe, 1928; Vid. Revista de Occidente n 26, 1925, pp. $246-251$.

${ }^{53}$ En GARCÍA QUEIPO DE LLANO, op. cit.., pp. 308 y sig.

54 Vid. ROBLES CAICEDO, Laureano, «Miguel de Unamuno y Gerardo Diego (correspondencia)» en Ensayos: revista de la Escuela Universitaria de Magisterio de Albacete, № 3, 1989, pags. 109-136.

${ }^{55}$ Carta de G.D. a Artigas de 17-V-1926, en MORELLI, Op. Cit., pp. 116.

${ }^{56}$ FOM, Correspondencia Ortega, C-10-1, Gerardo Diego a Ortega, 8-XII-1927.
} 
política», frase de Dámaso Alonso para describir su infiltración en las vanguardias desde fines de 1927. Giménez Caballero ${ }^{57}$, que ya había publicado su «Conversación con un camisa negra» (15-II-1927), en referencia ambigua a Maeztu a quién trataba de implicar, publicaba la falsa entrevista «Gerardo Diego, poeta fascista» en El Sol (26-VII-1927), que encontrará rápido eco en la prensa santanderina:

«...es Gerardo Diego lo que Mussolini ha logrado en Italia. Y lo que proféticamente predecía Maura: la revolución desde arriba. Es decir. El vino revolucionario en odres tradicionales... De ahí ese aire de Junta Patriótica y de Somatén que ha tenido el Comité gongorino. Ese Comité que ha realizado actos de puro corte fascista...»

«Cuando usted publicó, en 1925, esos versos que le ascendieron a la simpatía oficial del Estado, con un premio solemne, hacia tiempo que ya fluctuaba usted, ¿verdad?... que ya veía las cosas de otro modo [...] Usted vio claro el fracaso revolucionario de la posguerra ¿verdad? Aquel internacionalismo comunista y anárquico Aquellos ataques a las fábricas del verso burgués [...] Las proclamas rojas del creacionismo le alistaron a usted en aquellas pléyades...» ${ }^{58}$.

En El Liberal, (31-VII-1927), Gerardo Diego es atacado por otro ultraísta, en este caso abiertamente contrario a la Dictadura, Ernesto López-Parra, con Los innovadores, acusándole de profascista, aparentando tomar en serio el artículo anterior: «... no tienen inconveniente en hacer un acto de fe en el homenaje a Góngora, que les sitúa dentro de las juventudes católicas de España...»59. Diego defiende su independencia pidiendo respeto por las posiciones religiosas, replicando en la revista Lola que imprime en Santander en enero de 1928 con «El señorito Góngora o una víctima del fascismo»:

«no soy fascista ni en política, ni en arte, ni en nada. Que soy igualmente ajeno a todo maurismo y a toda revolución desde arriba [...] pensamos y escribimos sin importarnos un rábano cuanto -en orden a un posible magisterio ideológico o estético-, piensan y escriben Unamuno, Ortega y Gasset, Jiménez y el propio magnífico Valle Inclán... ${ }^{60}$

La Gaceta Literaria, en noviembre de 1927, iniciaba una encuesta a escritores en la que Diego volvía a hacer gala de su nulo interés por la política, además de ser de los más taxativos en sus respuestas e indicaba ante ¿Debe intervenir la política en la literatura?: "Soy tan lego en la una como en la otra», y ante ¿Siente usted la política?, respondía: «Me duele, pero no sé dónde»; y continuaba negando, ante la cuestión ¿Qué ideas considera fundamentales para el porvenir del

\footnotetext{
57 Vid. BASSOLAS, Carmen, La ideología de los escritores. Literatura y política en La Gaceta Literaria (1927-1932), Barcelona, Fontamara, 1975.

${ }^{58}$ El Sol, 26-VII-1927; El Faro, (Santander) 27-VII-1927 reproduce el «Gerardo Diego fascista».

${ }^{59}$ El Liberal, de 31-VII-1927.

60 Lola nำ2, enero 1928.
} 
Estado español? respondía «Ya le he dicho que no entiendo una palabra. Ni siquiera por qué me lo preguntan»61.

La controversia es rápidamente aprovechada por Pick, cuyo diario, crítico con el directorio, había sido censurado y suspendido en varias ocasiones; éste, precisamente en la ciudad de nacimiento de Gerardo Diego, le reprocha la escasa preocupación política de las vanguardias; llega a reirse de versos de Larrea «...bendigamos el confort de las hormigas..» y de las quemas infantiles de libros y, en «Dos juventudes, dos inteligencias», pone el ejemplo de Marañón, recién regresado de Cuba, que en medio de sus trabajos científicos encuentra tiempo para correr al Retiro al homenaje a Galdós «tendencia opuesta al gesto egoísta de los elementos de vanguardia», sentenciando que así se entiende la «Deshumanización del arte», aludiendo a Ortega, entendiendo que Goya, Cervantes o el propio Góngora vibraron con los problemas patrios, «no hay que contentarse con el salón de tertulias de la revista de Occidente».

Con motivo de la presencia en el ateneo santanderino de Sainz Rodríguez ( $L V C, 5-1-28:$ «El sabio profesor que vive como un estudiante»), le presenta como opositor a la Dictadura, pero que compagina dedicación literaria y vida pública, al igual que otro conservador y vanguardista, que frecuenta la tertulia de Pombo, Rafael Calleja, que esas semanas había conferenciado también en el ateneo sobre la peligrosa situación de Rusia, lo que le sirve para sentenciar de nuevo que no es preciso ser avanzado políticamente como Marañón, para implicarse: «Gerardo Diego dice que él no entiende de política, pero que le duele. Y José del Río asegura que ya que le pica la política que se rasque, es decir, que hable...». Entiende Pick que faltan ideales en estos poetas: «...los viejos son los románticos de ahora, los que apostrofaron a los jóvenes caducos de la vanguardia»62. Diego reticente a las implicaciones ideológicas y reacio a dejarse llevar por las polémicas de prensa, argumenta sus motivos en una de sus frecuentes cartas a José María de Cossío:

«Leerías mi artículo mutilado por la censura [en LVC, el censor gubernamental le tacha unas líneas] y la réplica de Río. Yo no intervengo más. No tengo ganas de trabajar gratis para llenarles columnas y acrecentar peligrosas polémicas en La Voz de Cantabria. Además con Río es imposible porque domina las tangentes, las lisonjas y los sarcasmos, y no se ciñe a la honrada verdad»63.

Diego se disculpa («Al margen de unos artículos», LVC 11-1-1928): «¿Quiere que le hable a mis alumnos de política?, Los Deberes éticos y cívicos para alumnos de 12 años están a cargo de otro compañero" ¿Cómo escribir de lo que no entiendo? Tiene tachadas varias líneas [...] los Marañón se arman también su correspondiente lío...» No es Pick el único que aboga por el retorno a una literatura

\footnotetext{
${ }^{61}$ En GARCÍA QUEIPO DE LLANO, Op. Cit.., pp. 348.

62 LVC, 8-I-1928 y LVC, 7-I-1928: «Dos juventudes, dos inteligencias».

${ }^{63}$ GÓMEZ DE TUDANCA, Epistolario... [117] GD: Gijón, 15 de enero de 1928. El editor Rafael Calleja conferenciaba con «Cosas de Rusia en el ateneo» (12-IX-1927).
} 
más comprometida; otro joven ateneísta, el luego escritor falangista Maximiano García Venero, recién cumplidos veinte años, desde una posición de agitador político apuntaba poco antes en La Región (17-XI-1927) sobre el mismo tema de una necesaria implicación de los jóvenes que estima están olvidando la participación pública, comentando sobre la indiferencia:

«Hace veinte años, las boinas carlistas y los gorros frigios, se ostentaban orgullosos [...] la juventud no tenía ese nivel medio de indiferencia política que posee hoy. Hace veinte años ningún mozo hubiera comulgado en el altar que se ofrenda al arte por el arte [...]; estrofas muertas, de los versos exangües, de las palabras sin corazón. Alguno es catedrático [por G. Diego]. Comprendemos el reproche de Pick».

Sin embargo como es bien conocido, esta generación del 27, cosmopolita y alejada de preocupaciones nacionales se radicaliza a fines de la Dictadura: la divergencia hacia comunismos y fascismos se manifiesta. La desaparición de La Gaceta Literaria, incapaz de aunar ambas tendencias, es indicador de cómo estas desavenencias darán paso a campos antagónicos ${ }^{64}$. Hecho paradójico ya que la generación partía de un deseo de independencia. En cualquier caso Gerardo Diego, que se dejaba ver durante estos años con frecuencia y conferenciaba en el Ateneo santanderino y en los Cursos de Verano de la Sociedad Menéndez Pelayo, en armónica compañía con varios miembros de la generación del 27, de todas las tendencias ideológicas, señalará su apreciación de que el fin de la Dictadura coincidió claramente con un súbito cambio ideológico:

«Todos vivimos y sufrimos la opresión del ambiente súbitamente afiebrado a partir de 1929 y la guerra nos separó a la fuerza. Pero la amistad no se rompió.... ${ }^{65}$.

A partir de mitad del 29 esta pureza artística iba desapareciendo de la generación y las vanguardias se radicalizaban, como hemos comentado, en un sentido u en otro, aunque las divergencias ideológica no impidieron las amistades.

\section{LA COLABORACIÓN CULTURAL VASCO-MONTAÑESA.}

No todo son controversias, estos años se había producido un movimiento de colaboración cultural con Bilbao en arte y literatura a iniciativa de ambos Ateneos, perseguido ya por intelectuales vascos como Carmelo de Echegaray amigo de Menéndez Pelayo. La aproximación había dado buenos frutos en contacto fecundo con Joaquín Zuazagoitia, Esteban Bilbao, Pedro Eguillor, destacando la pre-

\footnotetext{
${ }^{64}$ BASSOLAS, C., La ideología..., op. cit., pp. $24 .$.

${ }^{65}$ ABC, 9-V-1979, en Diego, Elena, «La amistad en el grupo del 27», Cuaderno Adrede, n 1, Fundación Gerardo Diego, Santander, 2005.
} 
sencia de Pedro Mourlane Michelena ${ }^{66}$ y de Ramón de Basterra ${ }^{67}$, diplomático y precursor de la idea de hispanidad, el Hidalgo vizcaíno que cantó la amistad de las dos Montañas, la romance y la euskaldún, como se afirmó en la reunión de los dos ateneos en enero-febrero de 1923; todos ellos eran tertulianos del bilbaíno Lyon d'Or imbuidos de amplia cultura clásica, aspecto que les vincula a Eugenio d'Ors.

El 22 de enero de 1923 se desplazan a Bilbao, los ateneístas Artigas, J. Mํㅡ de Cossío, Fernando Barreda y Elías Ortiz de la Torre, leyéndose poemas (Gustavo de Maeztu desea ilustrar a Pick y G. Diego dedica un poema a Esteban Bilbao) y días después viajarán el novelista Vicente Pereda y el pintor Ángel Espinosa; visitas devueltas por Basterra, el 4 de febrero, en compañía del presidente del Ateneo bilbaíno Manuel Aranaz, de Mourlane Michelena y de Pedro Eguillor, recibidos por el presidente del Ateneo santanderino Pombo lbarra y por el diputado Ruano, visitas devueltas en febrero y marzo ${ }^{68}$, en que Aranaz, diserta sobre costumbrismo y Joaquín Zuazagoitia, director del Museo de Bellas Artes de Bilbao, sobre el pintor vasco-montañés Iturrino, que expondrá meses después con cierta polémica en el ateneo, y estudia la obra del paisajista Riancho ${ }^{69}$. Gustavo de Maeztu, exponía la semana del golpe de Primo de Rivera en el Casino, siendo homenajeado con los inevitables versos de Pick y Ramiro de Maeztu conferenciaba en el ateneo. Precisamente Pedro Mourlane y el crítico de arte Zuazagoitia, clausuran una exposición de pintura y conferencian en septiembre de 1923 yen junio de 1927. Estas visitas sirven también para que los artistas cantabros se relaciones y descubran la obra de la escuela vasca. Algunos han querido ver acercamientos, como en Pancho Cossío a la temática marinera vasca, (aunque mas que el particularismo le interesa el arte puro, lo pictórico) influencias mutuas perceptibles en Ricardo Bernardo y claramente en Iturrino.

Tras unos roces por motivos nacionalistas, J.M e Cossío, entona el «Canto a la Ría de Bilbao» de Pick para demostrar que no existe animadversión hacia los vizcaínos, en el ateneo de Bilbao en junio de $1925^{70}$ y volverá a leerse, por Casanueva, versos del bilbaíno honoris causa (El Liberal de Bilbao, 8-4-1928), en la Casa de la Montaña, inaugurada en mayo del 26 en Bilbao en armonía cántabrovizcaína con presencia de Pick, Basterra, Mourlane, los alcaldes; en junio la Coral de Bilbao, con su famoso director Guridi, visita largamente Santander:

«Santander acogerá hidalgamente a la embajada fraterna. La pacificación la hicieron los artistas y los poetas. Fue la voz lírica y exaltada de Ramón de Basterra

\footnotetext{
${ }^{66}$ ORTEGA GALLARZAGOITIA, Elena «Pedro Mourlane Michelena: ideología y cultura», , Cuadernos de Alzate: revista vasca de la cultura y las ideas, 18, pp. 203-220.

${ }^{67}$ Pick, El Liberal de Bilbao, 21-VI-1928: «Adios a Ramón de Basterra».

${ }^{68} L A, 25$ y 27-II-1923: en portada a página completa «Confraternidad vasco-santanderina: El banquete en la Bilbaína», hablando de la obra de Basterra.Pombo, Pick y Soler al ateneo de Bilbao y al Círculo de Bellas Artes. LA 10-3-23: «Cuadros vascos» en el Ateneo: Aranaz, relatos populares y costumbrismo,.

${ }^{69}$ El Faro, 23-VI-1927 «El monótono, cándido, agrio y perverso Iturrino».

${ }^{70}$ ACT, Casanueva a Cossío 31-V-1925.
} 
quién predicó la buena nueva [...], Aranaz, Castellanos, Rodolfo Reyes, Joaquín Zuazagoitia, Gustavo Maeztu, Mourlane Michelena, y Pedro Eguilor, voz entonada e hidalga del viejo Bilbao... ${ }^{71}$.

Pocos años después - desplazada esta vez la creación artística hacia el pensamiento político- visitaba Artigas un Bilbao, por entonces punto fuerte de la derecha autoritaria española, el 21 de enero de 1927 presentado por Mourlane, conferenciando sobre Menéndez Pelayo ${ }^{72}$. El 22 de diciembre de 1928, de nuevo invitado por la Junta de Cultura de la Diputación bilbaína, volvía a acudir Artigas a concurridas charlas (presididas por Esteban Bilbao, presidente de la Diputación de Vizcaya y miembro de la Asamblea Nacional Consultiva) en el Instituto y la Casa de la Montaña bilbaína ${ }^{73}$, para homenajear al discípulo de Menéndez Pelayo, Carmelo Echegaray, fallecido pocos años atrás. Pero finalizada la Dictadura, el cambio se manifiesta pronto: a la prensa del nacionalismo vasco le molestan estos contactos; cuando Pick y Cossío visitan la tertulia de El Lyon d'Or, frecuentada también por Félix de Lequerica ${ }^{74}$, expresando su opinión de que la Dictadura había fracasado al infectar más el ambiente nacionalista, aspecto en lo que los tertulianos bilbaínos, varios de ellos menendezpelayistas y miembros de la Sociedad Menéndez Pelayo, disienten, desde Euzkadi de Bilbao (28-III-1930), se recoge la visita con burla hacia los de El Lyon: «hasta en Santander tienen que darles lecciones» ironizan sobre el intento fallido de asfixiar al nacionalismo por la recién caída Dictadura.

Finalizada la Dictadura, la presión de los acontecimientos hará virar a un cierto número de escritores y artistas, tanto hacia las derechas autoritarias, hacia radicalismos de izquierda, o hacia el grupo afín a un republicanismo liberal en el que militaban los influyentes Marañón u Ortega, con presencia de intelectuales santanderinos en la, por otro lado efímera, Agrupación al Servicio de la República (Ricardo Bernardo, Gerardo Diego, José del Río Pick, José María de Cossío, Arturo Casanueva, Manuel Ruiz de Villa...), páginas que también dejarán huella en el Ateneo.

\footnotetext{
${ }^{71}$ La Atalaya, Pick «Aire de la calle». Vid. EDM de 23-VI-1926.

72 El Sol 22-I-1927, pp. 5.

${ }^{73} \mathrm{El} \mathrm{Sol,} \mathrm{22-XII-1928.}$

${ }^{74}$ LVC, 10-X-1928, Pick: «El Rivadol del Lyon d Or», sobre Félix de Lequerica.
} 